\title{
Laparoscopic Nissen Fundoplication for Gastroesophageal Reflux Disease: A Retrospective Study of 50 Consecutive Cases
}

\author{
Yosuke Seki*, Tomomi Watanabe, Akiko Umezawa, Kazunori Kasama, Yoshimochi Kurokawa \\ Minimally Invasive Surgery Center, Yotsuya Medical Cube, Tokyo, Japan
}

Received: September 09, 2015; Accepted: October 28, 2015; Published: December 02, 2015

*Corresponding author: Yosuke Seki, Consultant surgeon, Yotsuya Medical Cube, Tokyo, Japan, 102-0084, Tel: +81-3-3261-0401, Fax: +81-3-32610402; E-mail: yosuke_seki@hotmail.com

\begin{abstract}
Background: Laparoscopic anti-reflux surgery has been proven to be an effective treatment for gastroesophageal reflux disease (GERD) in Western countries. On the other hand, the concept of surgical treatment of GERD has not widely spread in Japan, and the number of operations performed remains extremely low.

Purpose: The aim of this study is to analyze our initial experience with laparoscopic Nissen fundoplication.

Patients and Methods: From August 2010 to November 2012, consecutive 50 adult patients diagnosed with GERD underwent laparoscopic Nissen fundoplication. There were 42 men and 8 women, with an average age of $45.6 \pm 15.9$ years. All patients were resistant to medical treatment for GERD. Pre-operative endoscopy showed hiatal hernias in 47 patients (94\%), and Barrett's esophagus in 26 patients (52\%). In regard to mucosal change of the lower esophagus, 38 patients $(76 \%)$ were diagnosed as non-erosive gastroesophageal reflux disease (NERD) and the remaining 12 patients (24\%) as reflux esophagitis (RE).
\end{abstract}

Results: Laparoscopic approach was successfully done in all patients without conversion. Mean operative time was $105.9 \pm 22.7$ min with mean blood loss of $6.5 \pm 13.1 \mathrm{ml}$, and mean post-operative hospital stay was $2.0 \pm 0.2$ days. There was no intra-operative complication and no mortality. There were 4 post-operative complications in 4 patients (8\%) during the mean follow-up period of $4.7 \pm 5.5$ months. The change in GERD symptoms was evaluated using FSSG (frequency scale for the symptoms of GERD) at each visit. The average total score was

$24.0 \pm 10.2$ before surgery and significantly dropped to $8.4 \pm 7.0$ at 6 months after surgery $(\mathrm{p}<0.05)$. PPIs were prescribed in 43 out of 50 patients $(86 \%)$ before surgery and the percentage dropped to $8.7 \%$ ( 4 out of 46 patients) at the latest visit. Overall efficacy rate was $90 \%$.

Conclusion: Laparoscopic Nissen fundoplication for medically uncontrolled GERD is safe and effective also in the Japanese population. Considering the recent rapid increase of obesity and westernized life style, the necessity of the treatment will be more and more important.

Keywords: Gastroesophageal Reflux Disease; Laparoscopic Fundoplication; GERD; NERD; Nissen; Japanese

\section{Introduction}

Gastroesophageal reflux disease (GERD) is a common condition, experienced by up to $20 \%$ of the population in Western countries [1] and although the data vary with the reports, up to $4.0-19.9 \%$ of the Japanese population [2-5]. Treatment of GERD includes a range of options and can be divided into three progressive steps. The first are changes to lifestyle, whereby overweight patients are advised to lose weight, reduce smoking/ alcohol consumption, and to alter dietary and sleeping patterns. The second tier of treatment is the use of acid suppression therapy, using either histamine receptor antagonists (H2RA) or PPIs, followed by maintenance use of these acid suppression drugs. Surgery is currently considered the third tier of management and is usually confined to patients with severe symptoms which are not adequately controlled.

Surgical treatment of GERD has been shown to be effective by level I evidence (randomized controlled trials) compared to medical treatment, both in terms of symptom control and quality of life [6-12], and has been well established as one of the options in Western countries. According to data from the Nationwide Inpatient Sample in the United States, the annual number of antireflux procedures performed in the United States was 31,695 in 1999 and 23,998 in 2003 [13]. On the other hand, according to the most recent nationwide survey of endoscopic surgery in Japan, the number of laparoscopic anti-reflux surgery performed in 2011 was only 172 [14]. Thus, even allowing for the racial and cultural differences between Westerners and Japanese, the penetration of surgical treatment of GERD in Japan is very low. One possible reason would be that surgeons in Japan have limited experience of laparoscopic surgery for GERD. Another would be that many of the primary care physicians who usually take care of the condition, often do not know much about the effect of the surgical treatment, especially in the modern era of laparoscopic surgery. In this report, we show our initial experience of laparoscopic Nissen fundoplication for GERD among medically uncontrolled Japanese patients.

\section{Patients and Methods}

From August 2010 to November 2012, consecutive 50 adult patients diagnosed with GERD underwent laparoscopic Nissen 
fundoplication. Indications for surgery were set according to the SAGES guidelines in 2010, which are those who: (1) have failed medical management (inadequate symptom control, severe regurgitation not controlled with acid suppression, or medication side effects); (2) opt for surgery despite successful medical management (due to quality of life considerations, lifelong need for medication intake, expense of medications, etc.); (3) have complications of GERD (e.g. Barrett's esophagus, peptic stricture); (4) have extra-esophageal manifestations (asthma, hoarseness, cough, chest pain, aspiration) [15]. Pre-operative evaluations consisted of detailed interview/questionnaire regarding the presence or absence of subjective symptoms; endoscopic findings of the esophagus; and barium investigations of the esophagus. Ambulatory 24-hour pH monitoring was also performed arbitrarily.

Patients were placed in a supine position under general anesthesia, and two $12-\mathrm{mm}$ ports and three 5 -mm ports were inserted. The surgical procedure involved resecting the short gastric vessels, mobilization of the gastric fundus, division of the phrenoesophageal ligament, and dissecting tissue around the esophagus to obtain at least $3 \mathrm{~cm}$ of abdominal esophagus. Anterior and posterior branches of vagus nerve were visualized and preserved. Calibration at crural repair was done using a $45-\mathrm{F}$ bougie inserted into the esophagus, according to the floppy Nissen fundoplication. After a "shoeshine" maneuver was done to prevent undue tension, 360 degree wrapping of the gastric fundus was done with three stitches and a width of $1.5-2 \mathrm{~cm}$. A naso-gastric tube was not placed. Oral intake started from the first postoperative day, after confirming the passage of the plicated esophagogastric junction by swallowing contrast medium.

Patients' demographics, symptoms, results of preoperative studies, operative data, postoperative complications, and surgical outcomes were collected from medical records. Data were analyzed using SPSS software (Chicago, IL, USA). For comparison, the Wilcoxon signed-rank test was used, and $\mathrm{P}$ values of less than 0.05 were considered significant. Results were expressed as mean \pm SD.

\section{Results}

There were 42 males and 8 females with an average age of $45.6 \pm 15.9$ years (range: $19-76$ years). Mean time of duration of symptoms was $6.2 \pm 6.9$ years (range: 6 months-20 years). All patients were resistant to conventional medical treatment for GERD, including 43 patients (86\%) taking proton pump inhibitors (PPIs). Pre-operative studies showed hiatal hernias in 47 patients (94\%). Barrett's esophagus was present in 26 (52\%), and reflux esophagitis in 12 (24\%) (Table 1).

Laparoscopic Nissen fundoplication without open conversion was successfully done in all patients. One patient underwent concomitant laparoscopic cholecystectomy. Mean skin to skin operative time was $105.9 \pm 22.7 \mathrm{~min}$, with mean blood loss of $6.5 \pm 13.1 \mathrm{ml}$, and mean post-operative hospital stay of $2.0 \pm$ 0.2 days. Transition of the skin to skin operative time and intraoperative blood loss in our series are shown in Figure 1. Both
Table 1: Pre-operative endoscopic findings of the 50 patients.

\begin{tabular}{|c|c|}
\hline $\begin{array}{l}\text { Modified Los Angels } \\
\text { classification }\end{array}$ & \\
\hline Grade 0 (normal appearance) & $8(16 \%)$ \\
\hline Grade M (minimal change) & $30(60 \%)$ \\
\hline Grade A & $8(16 \%)$ \\
\hline Grade B & $2(4 \%)$ \\
\hline Grade C & $2(4 \%)$ \\
\hline Grade D & $0(0 \%)$ \\
\hline \multicolumn{2}{|l|}{ Hiatal hernia } \\
\hline No & $3(6 \%)$ \\
\hline mild & $25(50 \%)$ \\
\hline Moderate & $17(34 \%)$ \\
\hline severe & $4(8 \%)$ \\
\hline \multicolumn{2}{|l|}{ Barrett's Esophagus } \\
\hline No & $24(48 \%)$ \\
\hline SSBE & $25(50 \%)$ \\
\hline LSBE & $1(2 \%)$ \\
\hline
\end{tabular}

intra-operative complication and mortality were nil. There were 4 post-operative complications that occurred in 4 patients (8\%) during the mean follow-up period of $4.7 \pm 5.5$ months (range: 2 days to 25 months, follow-up rate: $92 \%$ ). They included one gastroesophageal junction obstruction caused by residue on POD 14 which required endoscopic removal; one prolonged gas-bloating which occurred immediately after the operation and has still existed even after 4 months despite the continuous administration of antiflatulents; one mild recurrence which was controlled by PPI on demand; and one wrap herniation into the mediastinum revealed 20 months after the operation and subsequently fixed laparoscopically (Figure. 2).

Improvement of post-operative symptoms was evaluated using FSSG (frequency scale for the symptoms of GERD) at each visit. The FSSG consists of 12 simple questionnaires to evaluate the subjective symptoms of GERD and has been well validated in the literature, especially in Japanese patients [15-17]. The average total score (higher FSSG score indicating more likely to be GERD) before surgery was $24.0 \pm 10.2$. Immediately after surgery the score dropped significantly, to: $11.1 \pm 7.0$ at 1 week; $11.3 \pm 7.2$ at 1 month; $8.9 \pm 6.7$ at 3 months; and $8.4 \pm 7.0$ at 6 months ( $\mathrm{p}<0.05)$ (Figure. 3). Before surgery various kinds and doses of PPIs were prescribed in 43 out of 50 patients (86\%), and their symptoms were not fully controlled. After surgery at the latest visit only 4 out of 46 (excluding 4 patients lost to follow-up) (8.7\%) needed either continuous, or on demand, PPI administration. In 5 out of 50 patients $(10 \%)$ their subjective GERD symptoms were not ameliorated after surgery, which accounted for the overall efficacy rate of $90 \%$.

\section{Discussion}

Gastroesophageal reflux disease (GERD) is a common 


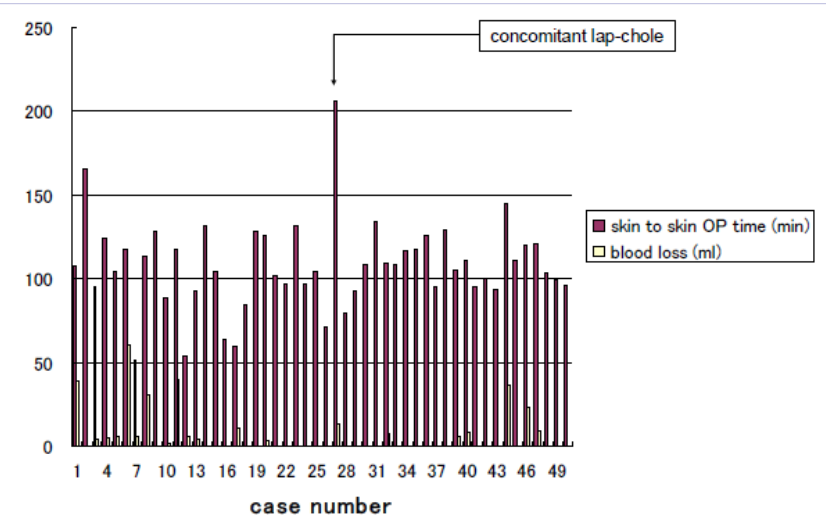

Figure 1: Leaning curve of laparoscopic Nissen fundoplication in our series.
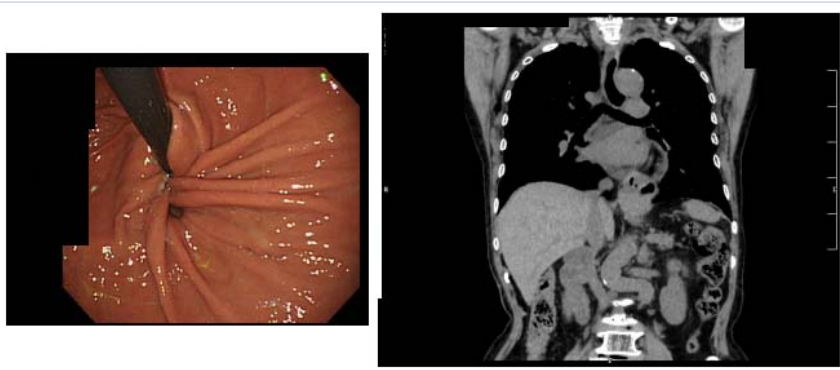

Figure 2: Wrap herniation into mediastinum which revealed 20 months after the primary lap-Nissen in a 74-year-old female. Her main complaint was dysphagia. Laparoscopic redo was successfully performed and the condition normalized.

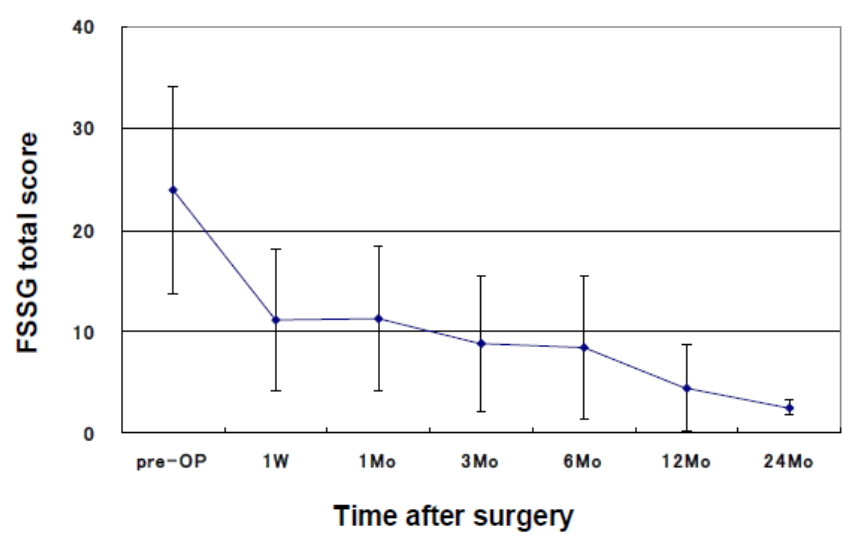

Figure 3: Change in subjective symptoms score.

condition affecting up to $20 \%$ of the population in Western countries (1). Although life style modification such as change in dietary and sleeping patterns is considered to be the first thing to do, there has been little evidence showing its clinical effectiveness [18]. Thus, realistically, the main actor in the treatment of GERD is acid suppression therapy such as histamine receptor antagonists (H2RA) and proton-pomp inhibitors (PPIs). The pharmacological therapy, especially PPIs, is actually very effective with an $84 \%$ efficacy rate for healing the endoscopic esophagitis, and 77\% for symptom control (heartburn relief) [19]. However, there are still about $10-20 \%$ of patients estimated to be resistant to the above mentioned medical therapy, which is huge considering the high prevalence of the disease. Also, the situation is even worse in patients with non-erosive gastroesophageal reflux disease (NERD) which have been shown to be more resistant than those with reflux esophagitis (RE) [20,21]. Therefore surgery becomes an important decision branch for those who are resistant to medical therapy.

Surgical treatment for GERD has been shown to be effective by level I evidence (randomized controlled trials) even compared to medical treatment, both in terms of symptom control and quality of life [6-12], and has been well established as one of the options in Western countries. In Japan, according to the most recent nationwide survey in 2011, the number of (laparoscopic) anti-reflux operations performed was only 172 a year [14]. Considering that the reported prevalence of GERD in Japanese adults is $4.0-19.9 \%$ [2-5], and that there is no obvious evidence so far that the efficacy rate of PPIs differs between Westerners and Japanese, the penetration of surgical treatment of GERD in Japan has to be considered as extremely low. In other words, there may be potentially a large number of patients whose GERD is inadequately treated. One possible reason would be that surgeons in Japan have limited experience of laparoscopic surgery for GERD. Another would be that many of the primary care physicians who usually take care of the condition do not know much about the concept, and the effect, of surgical treatment in the modern era of laparoscopic surgery.

There are already several reports showing the effects of surgical treatment of GERD in Japanese patients. Takeyama et al., reported their experience of 23 patients who underwent laparoscopic Nissen fundoplication. They examined the changes in GERD-related symptoms, endoscopic findings, gastroesophagogram findings and the results of intraesophageal 24-h pH monitoring, and concluded that the effectiveness of the operation was $89.5 \%$, with acceptable complication rates [22]. Omura et al., reported their experience of 22 NERD patients undergoing laparoscopic fundoplication (Nissen in 10 patients and Toupet in 12 patients). This is a very important study because more than half of GERD patients in Japan are in the state of NERD [23] and, as mentioned above, NERD patients are more likely to be resistant to medical therapy [20,21]. 91\% of their patients had a sliding hernia and $95 \%$ had a loose cardiac orifice detected in pre-operative endoscopy. They established their own surgical indications for NERD as follows: positive acid reflux on $\mathrm{pH}$ monitoring $(\mathrm{pH}<4$ time fraction: $4 \%$ or more); positive bilirubin reflux detected by Bilitec2000 (abs $>0.14: 4 \%$ or more); improvement of symptoms by $50 \%$ or more with the administration of a PPI, but with a desire not to continue longterm administration; symptoms of esophageal hiatal hernia and reflux other than heartburn, including regurgitation, belching, and epigastric discomfort. Under these indications they reported an overall efficacy rate of $95 \%$, and 21 out of the 22 patients achieved discontinuation of PPIs [24]. 
In our series, $76 \%$ of the patients (38 out of the 50 ) were diagnosed as NERD and $94 \%$ of them had hiatal hernias in various degrees. Before surgery PPIs were prescribed in $86 \%$ of the patients and the percentage dropped to $8.7 \%$ at the latest visit. Our overall symptom-based efficacy rate was $90 \%$, which is similar to the previous reports for Japanese patients.

The learning curve for laparoscopic anti-reflux surgery has been well documented in the literature with reports of increased failure rates [25], complications [26], re-operations [26], operative time [27], hospital days [27], and conversions to open surgery $[26,27]$ by less experienced surgeons. The learning phase for laparoscopic anti-reflux surgery is reported to be 15-20 cases and studies have suggested that surgeons seek experienced supervision during their learning period to minimize adverse outcome [26]. Also, good results have been reported by young surgeons after appropriate training in laparoscopy [28,29]. In our series, we experienced neither open conversion nor surgical mortality. The post-operative complication rate (including minor ones) of $8 \%$ is thought to be acceptable [30]. We did not see any specific learning effect regarding the operative time and the blood loss throughout the series as shown in figure 1. Probably this is because we introduced the operation after extensive experience of general MIS including bariatric surgery.

A limitation of the study is that the number of patients is small, and the follow-up period is relatively short. Also, we basically made the decision of efficacy of the treatment by a symptom scale, which is well-validated in the literature but subjective none the less. In conclusion, laparoscopic Nissen fundoplication is effective in controlling symptoms of GERD in Japanese patients. Since our experience is still limited, a study of larger scale could define more clearly the efficacy of this treatment modality.

\section{References}

1. Dent J, El-Serag HB, Wallander MA, Johansson S . Epidemiology of gastroesophageal reflux disease: a systematic review. Gut 2005;54(5):710-717.

2. Shimazu T, Matsui T, Furukawa K, Oshige K, Mitsuyasu T, Kiyomizu A, et al. A prospective study of the prevalence of gastroesophageal reflux disease and confounding factors. J Gastroenterol. 2005;40(9):866872

3. Mishima I, Adachi K, Arima N, Amano K, Takashima T, Moritani M, et al Prevalence of endoscopically negative and positive gastroesophageal reflux disease in the Japanese. Scand J Gastroenterol 2005;40(9):10051009.

4. Furukawa $\mathrm{N}$, Iwakiri $\mathrm{R}$, Koyama $\mathrm{T}$, Okamoto $\mathrm{K}$, Yoshida $\mathrm{T}$, Kashiwagi Y, et al. Proportion of reflux esopagitis in 6010 Japanese adults: prospective evaluation by endoscopy. J Gastroenterol. 1999;34(4):441-444

5. Fujiwara Y, Higuchi K, Watanabe $Y$, Shiba M, Watanabe T, Tominaga $\mathrm{K}$, et al. Prevalence of gastroesophageal reflux disease symptoms in Japan. J Gastroenterol Hepatol. 2005;20(1):26-29.

6. Spechler SJ, Lee E, Ahnen D, Goyal RK, Hirano I, Ramirez F, et al. Longterm outcome of medical and surgical therapies for gastroesophageal reflux disease: follow-up of a randomized controlled trial. JAMA. 2001;285(18):2331-2338.
7. Anvari M, Allen C, Marshall J, Armstrong D, Goeree R, Ungar W, et al. A randomized controlled trial of laparoscopic Nissen fundoplication versus proton pump inhibitors for treatment of patients with chronic gastroesophageal reflux disease: One-year follow-up. Surg Innov. 2006;13(4):238-249.

8. Mahon D, Rhodes M, Decadt B, Hindmarsh A, Lowndes R, Beckingham I, et al. Randomized clinical trial of laparoscopic Nissen fundoplication compared with proton-pump inhibitors for treatment of chronic gastro-oesophageal reflux. Br J Surg. 2005;92(6):695-699.

9. Mehta S, Bennett J, Mahon D, et al. Prospective trial of laparoscopic Nissen fundoplication versus proton pump inhibitor therapy for gastroesophageal reflux disease: Seven-year follow-up. J Gastrointest Surg. 2006;10(9):1316-1317.

10.Lundell L, Miettinen P, Myrvold HE, Pedersen SA, Thor K, Lamm M et al. Long-term management of gastro-esophageal reflux disease with omeprazole or open antireflux surgery: results of a prospective, randomized clinical trial. The Nordic GORD Study Group. Eur J Gastroenterol Hepatol. 2000;12(8):879-887.

11. Lundell L, Attwood S, Ell C, Fiocca R, Galmiche JP, Hatlebakk J, et al. Comparing laparoscopic antireflux surgery with esomeprazole in the management of patients with chronic gastro-esophageal reflux disease: a 3-year interim analysis of the LOTUS trial. Gut 2008;57:1207-1213. doi: 10.1136/gut.2008.148833.

12. Lundell L, Miettinen P, Myrvold HE, Hatlebakk JG, Wallin L, Malm A, et al. Seven-year follow-up of a randomized clinical trial comparing proton-pump inhibition with surgical therapy for reflux esophagitis. Br J Surg. 2007;94(2):198-203.

13. Finks JF, Wei $Y$, Birkmeyer JD. The rise and fall of antireflux surgery in the United States. Surg Endosc 2006;20(11):1698-1701.

14.11th Nationwide Survey of Endoscopic Surgery in Japan. Journal of Japan Society for Endoscopic Surgery 2012:17(5):572-694.

15. Kusano M, Shimoyama Y, Sugimoto S, Kawamura O, Maeda M, Minashi $\mathrm{K}$, et al. Development and evaluation of FSSG: frequency scale for the symptoms of GERD. J Gastroenterol. 2004:39(9):888-891.

16. Tsuboi K, Omura N, Yano F, Kashiwagi H, Yanaga K. Relationship of the frequency scale for symptoms of gastroesophageal reflux disease with endoscopic findings of cardiac sphincter morphology. J Gastroenterol. 2008;43(10):798-802. doi: 10.1007/s00535-008-2228-z

17. Danjo A, Yamaguchi K, Fujimoto K, Saitoh T, Inamori M, Ando T, et al. Comparison of endoscopic findings with symptom assessment systems (FSSG and QUEST) for gastroesophageal reflux disease in Japanese centres. J Gastroenterol Hepatol. 2009;24(4):633-638. doi: 10.1111/j.1440-1746.2008.05747.x.

18. Kaltenbach T, Crockett S, Gerson LB. Are lifestyle measures effective in patients with gastroesophageal reflux disease? An evidence-based approach.Arch Intern Med. 2006;166(9):965-971.

19. Chiba N, De Gara CJ, Wilkinson JM, Hunt RH. Speed of healing and symptom relief in grade II to IV gastroesophageal reflux disease: a meta-analysis. Gastroenterology. 1997;112(6):1798-1810.

20. Fass R, Shapiro M, Dekel R, Sewell J. Systematic review: proton-pump inhibitor failure in gastro-oesophageal reflux disease-where next? Aliment Pharmacol Ther. 2005;22(2):79-94.

21. Dean BB, Gano AD Jr, Knight K, Ofman JJ, Fass R. Effectiveness of proton pump inhibitors in nonerosive reflux disease. Clin Gastroenterol Hepatol. 2004;2(8):656-664. 
22. Takeyama S, Numata A, Nenohi M, Shibata Y, Okushiba S, Katoh H Laparoscopic Nissen fundoplication for gastroesophageal reflux disease in Japan. Surg Today. 2004;34(6):506-509.

23. Fujiwara Y, Arakawa T. Epidemiology and clinical characteristics of GERD in the Japanese population. J Gastroenterol 2009;44(6):518534. doi: 10.1007/s00535-009-0047-5.

24. Omura N, Kashiwagi H, Yano F, Tsuboi K, Ishibashi Y, Kawasaki N, et al. Therapeutic effects of laparoscopic fundoplication for nonerosive astroesophageal reflux disease. Surg Today. 2006;36(11):954-960.

25. Soper NJ, Dunnegan D. Anatomic fundoplication failure after laparoscopic antireflux surgery. Ann Surg. 1999;229(5):669-676.

26. Watson DI, Baigrie RJ, Jamieson GG. A learning curve for laparoscopic fundoplication. Definable, avoidable, or a waste of time? Ann Surg. 1996;224(2):198-203.
27. Deschamps C, Allen MS, Trastek VF, Johnson JO, Pairolero PC. Early experience and learning curve associated with laparoscopic Nissen fundoplication. J Thorac Cardiovasc Surg. 1998;115(2):281-284.

28. Contini S, Bertele A, Nervi G, et al. Quality of life for patients with gastroesophageal reflux disease 2 years after laparoscopic fundoplication. Evaluation of the results obtained during the initial experience. Surg Endosc 2002;16:1555-1560.

29. Contini S, Scarpignato C. Does the learning phase influence the late outcome of patients with gastroesophageal reflux disease after laparoscopic fundoplication? Surg Endosc. 2004;18(2):266-271.

30. Attwood SE, Lundell L, Ell C, Galmiche JP, Hatlebakk J, Fiocca R, et al. Standardization of surgical technique in antireflux surgery: the LOTUS Trial experience. World J Surg 2008;32:995-998. doi: 10.1007/ s00268-007-9409-4. 